Editorial

\title{
Opinión de experto - esquina posterolateral - 7 consejos que nos ayudarán a manejar esa lesión
}

\author{
Opinion of an Expert - Posterolateral Corner - 7 Advices that help us to \\ Manage this Injuries \\ Rafael Calvo Rodriguez ${ }^{1}$ \\ ${ }^{1}$ Clínica Alemana, Departamento de Ortopedia y Traumatología, \\ Clínica Alemana, Santiago, Chile
}

Rev Chil Ortop Traumatol 2018;59:1-2.

\section{1. ¿Cuál es el principal método diagnóstico?}

R: En el diagnóstico de las lesiones de esquina posterolateral (EPL), juegan un rol importante la Exploración física, Radiografías de stress y Resonancia Magnética.

La exploración física permite determinar mediante test específicos el compromiso aislado o asociado de las estructuras de la esquina. Se deben considerar las lesiones asociadas. Ninguno de los test específicos por si solo tiene elevada sensibilidad ni especificidad, por lo que es obligatoria sumarlos en la evaluación clínica.

Las Rxs de estrés bilateral en $0-30^{\circ}$ por su parte, permiten objetivar los hallazgos al examen físico. Dependiendo de los milímetros de apertura, confirma las lesiones existentes (y su comparación con la extremidad contralateral descartan el componente de hiperlaxitud que puede ser un factor que confunda. La crítica a esas Rxs es que son operador dependiente, por lo que al utilizarlas se recomienda que sea el especialista el que realice las maniobras de estrés.

La resonancia por su parte, confirma el diagnóstico y descarta otras lesiones intra articulares que se pueden planificar de forma etapificada.

2. ¿Cuándo debemos considerar realizar el tratamiento conservador?

R: En general, las lesiones de esquina posterolateral no tienen potencial de cicatrización.

Solo debería estimarse un manejo conservador en pacientes con aperturas del espacio articular menor a $2,7 \mathrm{~mm}$ al estrés en varo (por eso la importancia de las Rxs de estrés), lo que estaría traduciendo un esguince de la esquina y no una rotura.

Actualmente, se considera que la clasificación IKDC para graduar los esguinces (en este caso de la EPL), subestiman el grado de lesión y una apertura de $<10 \mathrm{~mm}$ ya habla de un daño importante en la esquina que no cicatrizará con manejo conservador. En el estudio inicial de La Prade, se confirmó que aperturas $>2,7 \mathrm{~mm}$ hablan de lesión aislada completa del LCL, $>4 \mathrm{~mm}$ lesión completa de EPL, $>6,6 \mathrm{~mm}$ lesión combinada de EPL + LCA y $>$ 7,8 mm lesión de EPL + LCA + LCP.

\section{3. 'Timing' quirúrgico de la Lesión Aguda}

$\mathrm{R}$ : Generalmente, el manejo de esas lesiones requiere un periodo de espera inicial que permita la resolución del edema de partes blandas y contusiones asociadas. Además, se espera un mínimo rango de movimiento óptimo para evitar complicaciones como artrofibrosis. El timing inicial es conservador con férula ROM hasta conseguir un rango mínimo $0-90^{\circ}$ apoyado con rehabilitación motora $\mathrm{y}$ planificar la resolución quirúrgica no antes de 2-3 semanas.

\section{Lesiones Agudas}

¿Reparar o reconstruir?

R: Este tópico está actualmente más definido en la literatura, siendo la reconstrucción la opción que otorga significantemente mejores resultados clínicos que la reparación en lesiones agudas.

La única indicación de reparación en lugar de la reconstrucción, serían las lesiones avulsivas óseas (ej: fractura arcuata).

\section{Nuestro abordaje quirúrgico de elección}

¿Abierto o artroscópico mini open?

$\mathrm{R}$ : Con el fin de realizar una reconstrucción anatómica de las estructuras lesionadas, se requiere la ubicación precisa de puntos bien definidos que necesitan un abordaje abierto formal.

6. Fijación de la reconstrucción en lesiones multiligamentosas

R: Este es un tópico controversial en la literatura. No existen estudios biomecánicos a la fecha que otorguen la secuencia más indicada.

El grupo de La Prade recomienda la siguiente secuencia: LCP, EPL, LCA y EPM (para la reconstrucción en un tiempo).
Address for correspondence Rafael Calvo, MD, Editor Asociado, Revista Chilena de Ortopedia y Traumatología; Departamento de Ortopedia y Traumatología, Clínica Alemana, Santiago, Chile (e-mail: rcalvo61@gmail.com).
DOI https://doi.org/ 10.1055/s-0038-1642598. ISSN 0716-4548.
Copyright $\odot 2018$ by Thieme Revinter Publicações Ltda, Rio de Janeiro, Brazil

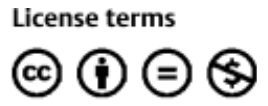


Nuestro grupo prefiere una cirugía etapificada en la cual se reconstruyen en primera instancia las esquinas y luego el pivote central.

\section{Indicaciones de la osteotomía}

R: En relación a las lesiones ligamentarias, la osteotomía está indicada en lesiones crónicas de la EPL asociadas a genu varo, doble o triple varo. Siempre que exista varus thrust, es necesario realizar un gesto adicional en el plano sagital (aumento slope tibial). La osteotomía es un gesto primario en lesiones crónicas, siendo la reconstrucción ligamentaria un procedimiento evaluable dependiendo de la estabilidad del seguimiento a 3-6 meses o en concomitancia con la osteotomía (no existen estudios de seguimiento a largo plazo que permitan establecer lo que es mejor). 